\title{
Smoking Status and Body Size Increase Carbon Monoxide Concentrations in the Breathing Circuit During Low-Flow Anesthesia
}

\author{
Chin-Sheng Tang, MS*, Shou-Zen Fan, MD, PhDt, and Chang-Chuan Chan, ScD $\ddagger$
}

*Department of Environmental Engineering and Health, Yuanpei Technical College, +National Taiwan University Hospital, College of Medicine, National Taiwan University, and łInstitute of Occupational Medicine and Industrial Hygiene, College of Public Health, National Taiwan University, Taipei, Taiwan

The major sources for intraoperative carbon monoxide (CO) in the breathing circuit are related to patient's hemoglobin catabolism, smoking and the degradation between absorbent and anesthetics. We performed this study to evaluate their combined effects on $\mathrm{CO}$ production during low-flow anesthesia. We used a directmeasurement instrument to measure real-time CO concentrations in the breathing circuit during different anesthetic conditions for patients who received desflurane or isoflurane. By applying multiple linear regression models, we determined the significant factors related to $\mathrm{CO}$ concentrations in the circuit. We identified patients' smoking status, preoperative smoking and body weight as well as gas flow rates as important factors for affecting peak and time-weighted $\mathrm{CO}$ levels. These four factors predicted approximately $44.1 \%$ and $42.7 \%$ of peak and mean inspiratory CO concentrations respectively. We found that chronic and preoperative smokers and patients with larger body weights are associated with increased CO concentrations, whereas increase in gas flow rates could decrease $\mathrm{CO}$ concentrations. After controlling these four important factors, we found that inspiratory $\mathrm{CO}$ concentrations were not significantly associated with the choice of anesthetic and its concentration during low-flow anesthesia.

(Anesth Analg 2001;92:542-7)
$\mathbf{L}$ ow-flow anesthesia reduces anesthetic consumption and operating room pollution. However, this practice can result in the accumulation of carbon monoxide (CO) from the catabolism of hemoglobin (1). Low fresh gases also increase carboxyhemoglobin $(\mathrm{COHb})$ levels (2). One recent study reports that preoperative smoking, which is measured by expired breath CO concentration, increases ST depression for patients without a history of ischemic heart disease during general anesthesia (3). Many in vitro studies also report that the reaction between desiccated carbon dioxide $\left(\mathrm{CO}_{2}\right)$ absorbent and volatile anesthetics is a major source of $\mathrm{CO}$ production (desflurane $>$ isoflurane) (4-7). Real-time and continuous CO monitoring may identify exposure to large $\mathrm{CO}$ concentrations (8), especially for patients suffering from ischemic heart disease. The goal of this study is to measure $\mathrm{CO}$ concentrations continuously during low-flow anesthesia to determine the contribution of $\mathrm{CO}$ accumulation in the breathing circuits by different anesthetic

Accepted for publication October 20, 2000.

Address correspondence and reprint requests to Chang-Chuan Chan, ScD, Rm. 1447, 14F, No.1, Sec. 1, Jen-ai Rd., Taipei 100, Taiwan. Address e-mail to ccchan@ha.mc.ntu.edu.tw. conditions and patient characteristics, such as anesthetic types and concentrations, gas flow rates, gender, body weight, and smoking status.

\section{Methods}

Our IRB on human subjects has approved this study, and all participating patients have given their informed consents. We randomly selected 218 patients, who received inhaled anesthesia with desflurane or isoflurane for scheduled operations. Patients with pulmonary dysfunction, asthma, or who were receiving cardiac and vascular surgery were excluded. We recorded patient's age, sex, and body weight and obtained their smoking status, including smoking history, cigarette consumption per day, and preoperative smoking information. We defined patients as smokers if they had smoked at least one cigarette per day within the last month. We defined preoperative smoking as a patient's cigarette consumption before operation on the morning of surgery.

To measure $\mathrm{CO}$ exposures and variations during anesthesia, the anesthetic types, concentrations, and gas flow rates of inhaled anesthesia were decided by 


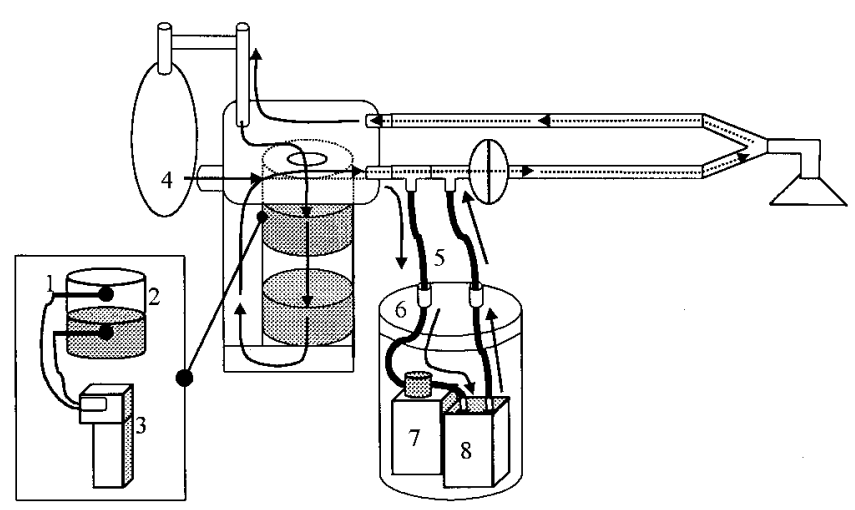

Figure 1. The direct-measurement system of monitoring intraoperative carbon monoxide $(\mathrm{CO})$ concentrations, temperature and relative humidity. $1=$ temperature and relative humidity sensor probe, 2 = upper canister, $3=$ temperature and relative humidity monitor, 4 = gas from anesthesia machine, $5=$ silicon tube and connector, 6 $=$ polyethylene sampling chamber, $7=$ direct-measurement $\mathrm{CO}$ monitor, $8=$ suction pump.

anesthesiologists. The choice of anesthetics, however, was not dependent on patients' smoking history. The anesthesiologists were not aware of our study design when they performed the anesthesia. Each day we replaced at least one canister of fresh soda lime (SODASORB $^{\circledR}$; W. R. Grace \& Co., Cambridge, MA) in the anesthesia machine (Modulus ${ }^{\circledR}$ CD Anesthesia System, Ohmeda Inc., Madison, WI) before the first induction of anesthesia. We recorded gas flow rates and concentrations of inhaled anesthesia intraoperatively and used time-weighted averages to represent gas flow rates and anesthetic concentrations for the entire period. We recorded the inhaled anesthetic concentrations from the gas monitor in the anesthesia machine that directly measured the anesthetic concentrations in the breathing circuit.

To monitor CO production from the degradation of anesthetics by dried $\mathrm{CO}_{2}$ absorbents, we modified the inspiratory limb of the breathing circuit to make realtime $\mathrm{CO}$ measurements in a bypass circuit (Fig. 1). We also modified the absorbent's canister to measure temperature and relative humidity in the gas phase intraoperatively. The CO monitor we used is based on an electrochemical oxidation principle (Drager PacIII CO detection instrument, Drager, Inc., Pittsburgh, PA). It has a detection range of from 1 to $2000 \mathrm{ppm}$ and records 10-s averaged concentrations continuously. Routine calibration of the $\mathrm{CO}$ monitor and suction flow rate of the pump was performed according to the manufacture's instructions. In practice, we used a pump (Dual mode low-flow air sampler, LFS-113, Gilian $^{\circledR}$; Sensidyne, Clearwater, FL) to draw approximately $500 \mathrm{~mL} / \mathrm{min}$ of gas from the inspiratory limb for continuous $\mathrm{CO}$ measurements and then it was returned to the circuit. We also put two probes (Testo 400 multifunction-measuring instrument, Testo $\mathrm{GmbH} \&$ Co., Lenzkirch, Germany) at the points
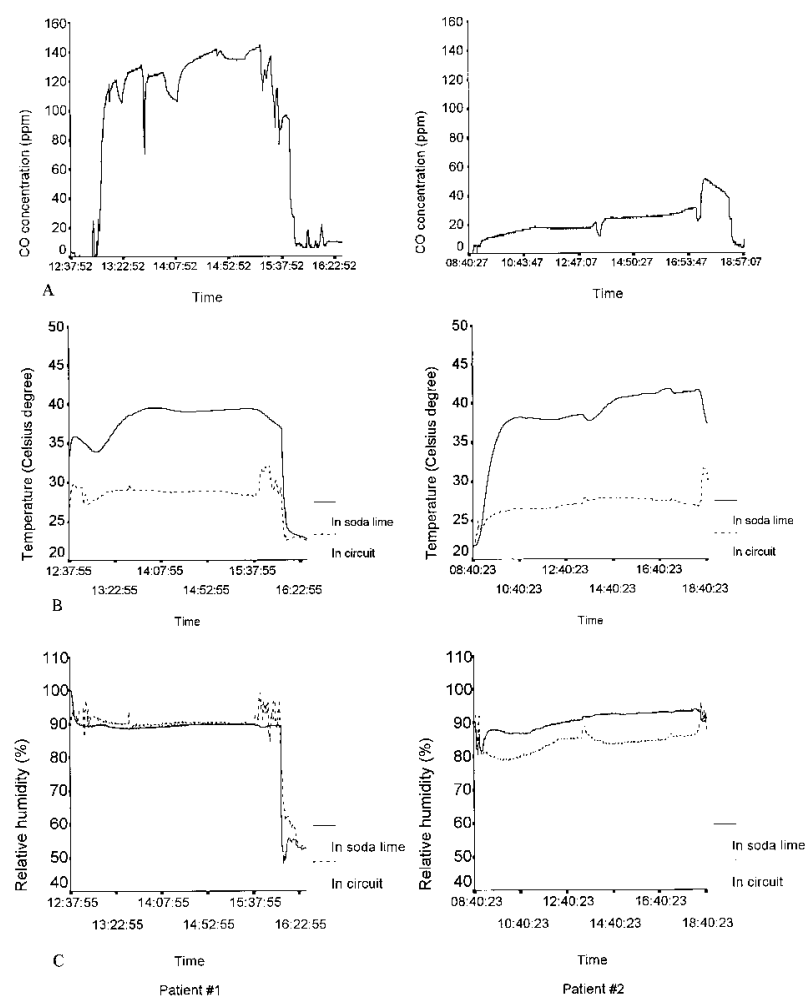

Figure 2. A typical example of intraoperative carbon monoxide (CO) concentration (A), temperature (B) and relative humidity (C) trends recorded by the direct-measurement system for two patients. Patient \#1: male, aged $54 \mathrm{yr}, 58.7 \mathrm{~kg}$, smoker, and 1 cigarette of preoperative smoking under the averaged concentration of $1.5 \%$ desflurane at $0.66 \mathrm{~L} / \mathrm{min}$ of averaged gas flow rate; Patient \#2: female, aged $29 \mathrm{yr}, 47 \mathrm{~kg}$, nonsmoker under the averaged concentration of $0.4 \%$ desflurane at $0.73 \mathrm{~L} / \mathrm{min}$ of averaged gas flow rate.

Table 1. Description of Patient's Characteristics $(n=218)$

\begin{tabular}{llcr}
\hline \multicolumn{1}{c}{ Item } & Category & Frequency & Percent \\
\hline Gender & Male & 117 & 53.7 \\
& Female & 101 & 46.3 \\
Smoking status & Smoker & 47 & 21.6 \\
& Nonsmoker & 171 & 78.4 \\
Number of cigarettes & & & \\
smoked per day & 0 & 171 & 78.4 \\
& $1 \sim 10$ & 12 & 5.5 \\
& $11 \sim 20$ & 26 & 11.9 \\
Number of cigarettes & $21 \sim 50$ & 9 & 4.2 \\
smoked before & & & \\
operation in & & & \\
smokers & 0 & 31 & 66.0 \\
& 1 & 12 & 25.5 \\
& 2 & 3 & 6.4 \\
Anesthetic used & 3 & 1 & 2.1 \\
& Desflurane & 149 & 68.3 \\
& Isoflurane & 69 & 31.7 \\
\hline
\end{tabular}

above and inside the absorbent canister to monitor changes of relative humidity and temperature in the circuit and absorbent during operation. The anesthesia 
Table 2. Description of Patient's Characteristics and Anesthetic Characteristics During Operation $(n=218)$

\begin{tabular}{|c|c|c|c|c|c|}
\hline \multirow[b]{2}{*}{ Item } & \multicolumn{5}{|c|}{ Statistics } \\
\hline & No. & Mean & SD & Maximum & Minimum \\
\hline Age (yr) & 218 & 38.7 & 23.0 & 84.5 & 0.1 \\
\hline Weight $(\mathrm{kg})$ & 218 & 51.5 & 20.9 & 117.0 & 0.9 \\
\hline Concentration of desflurane (\%) & 149 & 6.2 & 2.4 & 12.9 & 0.6 \\
\hline Concentration of isoflurane (\%) & 69 & 1.4 & 0.8 & 3.64 & 0.4 \\
\hline Concentration of peak CO (ppm) & 218 & 24.8 & 19.4 & 145.0 & 1.0 \\
\hline Concentration of mean $\mathrm{CO}(\mathrm{ppm})$ & 218 & 17.0 & 14.8 & 114.7 & 0.3 \\
\hline Flow rate of gas $(\mathrm{L} / \mathrm{min})$ & 218 & 1.4 & 0.9 & 4.8 & 0.3 \\
\hline Anesthesia duration (min) & 218 & 143.2 & 139.4 & 700.0 & 5.0 \\
\hline
\end{tabular}

$\mathrm{CO}=$ carbon monoxide

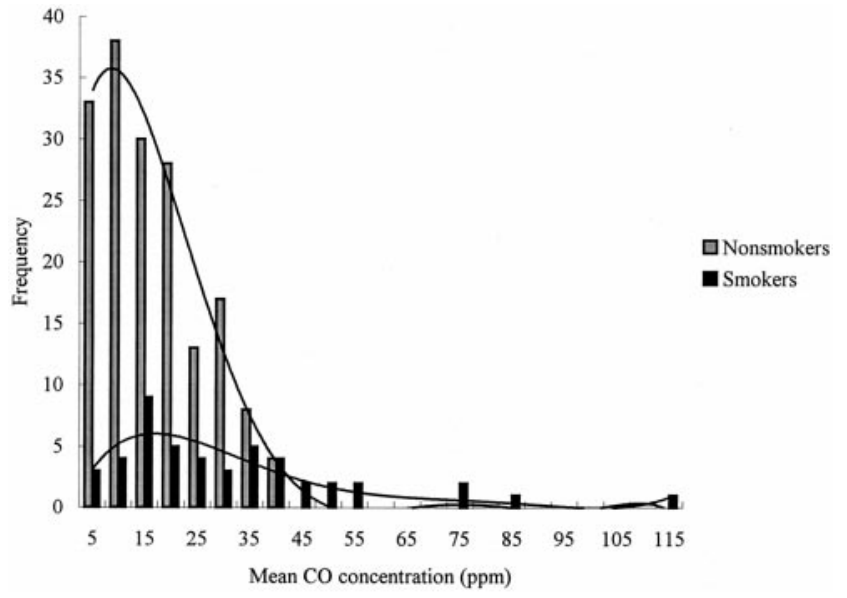

Figure 3. Histogram of inspiratory mean carbon monoxide (CO) concentrations for chronic smokers $(n=47)$ and nonsmokers $(n=$ 171).

machine and anesthetic circuit were purged with high fresh gas flows before each operation.

We applied multiple linear regression models to evaluate the contribution of various exogenous and endogenous factors to the patient's CO exposures. We used peak and time-weighted $\mathrm{CO}$ concentrations as dependent variables and patient's gender, body weight, smoking status, cigarettes smoked before operation, and gas flow rates, as well as anesthetic type as predictive variables in the models. We fit separate regression models to evaluate the relation between anesthetic concentrations and $\mathrm{CO}$ exposures for each type of anesthetic. We used SPSS software (SPSS for windows, Release 10.0.1; SPSS Inc., Chicago, IL) to perform data analysis and set a $P$ value $<0.05$ as statistically significant in the models.

\section{Results}

Our results indicate that our system could monitor intraoperative changes in $\mathrm{CO}$, temperature, and relative humidity continuously for over $10 \mathrm{~h}$ of anesthesia (Fig. 2). The demographic data of the patients and their characteristics during anesthesia are summarized in Tables 1 and 2.

The distribution of inspiratory $\mathrm{CO}$ concentrations in Figure 3 indicate that 48 of these 218 patients (22\%) exceeded the $35 \mathrm{ppm}$ time-weighted exposure limit for workers by US National Institute of Occupational Safety and Health environmental exposure limits in 1972. Among them, chronic smokers (22 of 47, 47\%) had a larger percentage of increased $\mathrm{CO}$ exposure than nonsmokers (26 of 171, 15\%). On average, the temperature was $35.7 \pm 5.0^{\circ} \mathrm{C}$ in the soda lime and $26.2 \pm 1.1^{\circ} \mathrm{C}$ in the breathing circuit during anesthesia. The relative humidity was $86.5 \pm 5.0 \%$ in the soda lime and $89.5 \pm 4.9 \%$ in the breathing circuit intraoperatively.

The results of multiple linear regression models listed in Table 3 show that smoking status, preoperative cigarette consumption, gas flow rate, and body weight were four significant predictive variables affecting $\mathrm{CO}$ concentrations. In total, they explained approximately $44.1 \%$ and $42.7 \%$ of the variance of peak and mean CO concentrations respectively. However, gender, anesthetic type, and concentrations had no significant effect.

From our regression model, the peak and mean CO concentrations of smokers were $11.5 \mathrm{ppm}$ and $7.5 \mathrm{ppm}$ more than nonsmokers $(P<0.01)$. The $\mathrm{CO}$ concentrations were positively related to preoperative cigarette consumption (8.1 ppm for mean and 9.5 ppm for peak $\mathrm{CO}$ concentrations per cigarette). Increase of gas flow rate was the major factor for reduced $\mathrm{CO}$ concentrations in the breathing circuit (7.7 ppm for peak $\mathrm{CO}$ and 5.9 ppm for mean CO decrease per L/min). There was a decreasing trend in $\mathrm{CO}$ concentrations with increasing gas flow rates, as shown in the scatter plot of Figure 4A. The scatter plot in Figure 4B showed that patient's body weight was positively associated with inspiratory $\mathrm{CO}$ concentrations and the increasing rates were approximately 0.2 ppm per $\mathrm{kg}$.

\section{Discussion}

In this study, we found that chronic smokers had a greater inherent probability of increased $\mathrm{CO}$ concentrations in the breathing circuits than nonsmokers. 
Table 3. Effects of Personal Attributes and Anesthetic Conditions on Carbon Monoxide (CO) Concentrations in the Breathing Circuit by Multiple Linear Regression Model

\begin{tabular}{|c|c|c|c|c|c|}
\hline \multirow[b]{2}{*}{ Dependent variable } & \multirow[b]{2}{*}{ Predictors } & \multicolumn{2}{|c|}{$\begin{array}{l}\text { Unstandardized } \\
\text { coefficients }\end{array}$} & \multirow[b]{2}{*}{$P$ Value } & \multirow[b]{2}{*}{ Adj. $r^{2}$} \\
\hline & & B & $\mathrm{SE}$ & & \\
\hline \multirow[t]{7}{*}{ Peak CO $(n=218)$} & Constant & 18.330 & 3.429 & 0.000 & \multirow[t]{7}{*}{0.441} \\
\hline & Smoker & 11.471 & 3.002 & 0.000 & \\
\hline & Pre-smoke & 9.537 & 3.009 & 0.002 & \\
\hline & Gas flow (L/min) & -7.661 & 1.068 & 0.000 & \\
\hline & Anesthetic & 3.926 & 2.157 & 0.070 & \\
\hline & Gender & -0.267 & 2.122 & 0.900 & \\
\hline & Body weight (kg) & 0.241 & 0.051 & 0.000 & \\
\hline \multirow[t]{7}{*}{ Mean CO $(n=218)$} & Constant & 12.152 & 2.653 & 0.000 & \multirow[t]{7}{*}{0.427} \\
\hline & Pre-smoke & 8.073 & 2.328 & 0.001 & \\
\hline & Smoker & 7.500 & 2.322 & 0.001 & \\
\hline & Gas flow (L/min) & -5.907 & 0.826 & 0.000 & \\
\hline & Anesthetic & 2.541 & 1.669 & 0.129 & \\
\hline & Body weight (kg) & 0.190 & 0.039 & 0.000 & \\
\hline & Gender & 0.048 & 1.642 & 0.977 & \\
\hline
\end{tabular}

Adj. $\mathrm{r}^{2}=$ adjusted R square; Peak $\mathrm{CO}=$ concentration $(\mathrm{ppm})$; Smoker $=0$, nonsmoker, 1 , smoker; Pre-smoke $=$ Number of cigarettes smoked before operation; Anesthetic $=0$, desflurane, 1 , isoflurane; Gender $=0$, male, 1 , female; Mean CO = concentration (ppm).

Significant for $P<0.05$.

Acute preoperative smoking also resulted in excess $\mathrm{CO}$ exposures for smokers. Figure 2 shows a significant difference (90 ppm) in $\mathrm{CO}$ concentrations between a preoperative smoker (Patient \#1) and nonsmoker (Patient \#2), even though gas flow rates, temperature, and relative humidity were not different. These differences likely result from the patients' personal attributes, such as smoking and body weight, than from the degradation of anesthetics.

We estimated that the average contribution of body weight to $\mathrm{CO}$ concentrations in the breathing circuit was approximately $0.2 \mathrm{ppm} / \mathrm{kg}$ in our regression model. We believe this estimate is reasonable because the contribution of body weight to $\mathrm{CO}$ in our breathing circuit for healthy and active persons should be within $2 \mathrm{ppm}$ if the $\mathrm{CO}$ production rate of $0.36 \pm 0.5$ $\mu \mathrm{mole} / \mathrm{hour} / \mathrm{kg}$ proposed by Bensinger et al. (9) is used.

We successfully demonstrated the electrochemical method to continuously measure the real-time variations of $\mathrm{CO}$ concentrations in the circuit. Our data also showed that under a steady gas flow rate, $\mathrm{CO}$ concentrations accumulated to a plateau level rapidly. Whenever gas flow rates increased suddenly, the CO concentrations decreased accordingly (Fig. 2). Bonome et al. (2) reported a similar result of fresh gas flow's diluting effect on $\mathrm{CO}$ concentrations in the circuit. Our regression model predicted the decrease of approximately $7.7 \mathrm{ppm}$ and $5.9 \mathrm{ppm}$ in peak and mean $\mathrm{CO}$ concentrations for an increase of gas flow rates by 1 $\mathrm{L} / \mathrm{min}$. Although low-flow is a current trend in anesthesia, we recommended that an increasing gas flow rate should be considered $(2,10)$ during anesthesia for smoking patients undergoing emergency and day surgery, especially for patients with excess body weights.
In this study, we found that anesthetic type and concentration did not significantly affect $\mathrm{CO}$ production. However, several in vitro studies have reported that desflurane produced more $\mathrm{CO}$ than isoflurane for a given minimum alveolar anesthetic concentration $(4,6)$ as well as a positive association between $\mathrm{CO}$ production rates and an increase in anesthetic concentrations (4). We could attribute such a discrepancy to the fact that the soda lime during our clinical use was not dried to the condition of previous in vitro studies. By using relative humidity measurements in gas phase as indirect evidence for the solid absorbent's dehydration condition, we believe that our soda lime was always maintained at good hydration conditions during daily use after the replacement of fresh soda lime before the first daily induction of anesthesia $(8,11)$. In comparison to other factors, such as smoking, gas flow rates and body weight, we believe that $\mathrm{CO}$ production from the degradation of anesthetics in the desiccated $\mathrm{CO}_{2}$ absorbents became less significant during actual clinical anesthesia.

Gas monitors, such as infrared, mass spectrometry $(12,13)$, and Raman spectroscopy monitors, cannot accurately quantify $\mathrm{CO}$ concentrations in the breathing circuit. Most of the $\mathrm{CO}$ concentration measuring methods used in previous studies used gas chromatography (GC) $(2,4,6,12,14,15)$ because of its specificity and sensitivity. However, the process of $\mathrm{CO}$ analysis by GC is time consuming and fairly complicated, and thus is not suitable for measuring real-time $\mathrm{CO}$ concentrations in the breathing circuit during operation. In contrast, the electrochemistry instrument used in this study performs a relatively fast (1 second response time), fully automated analysis and quantification of $\mathrm{CO}$ with good precision (1 ppm detection 

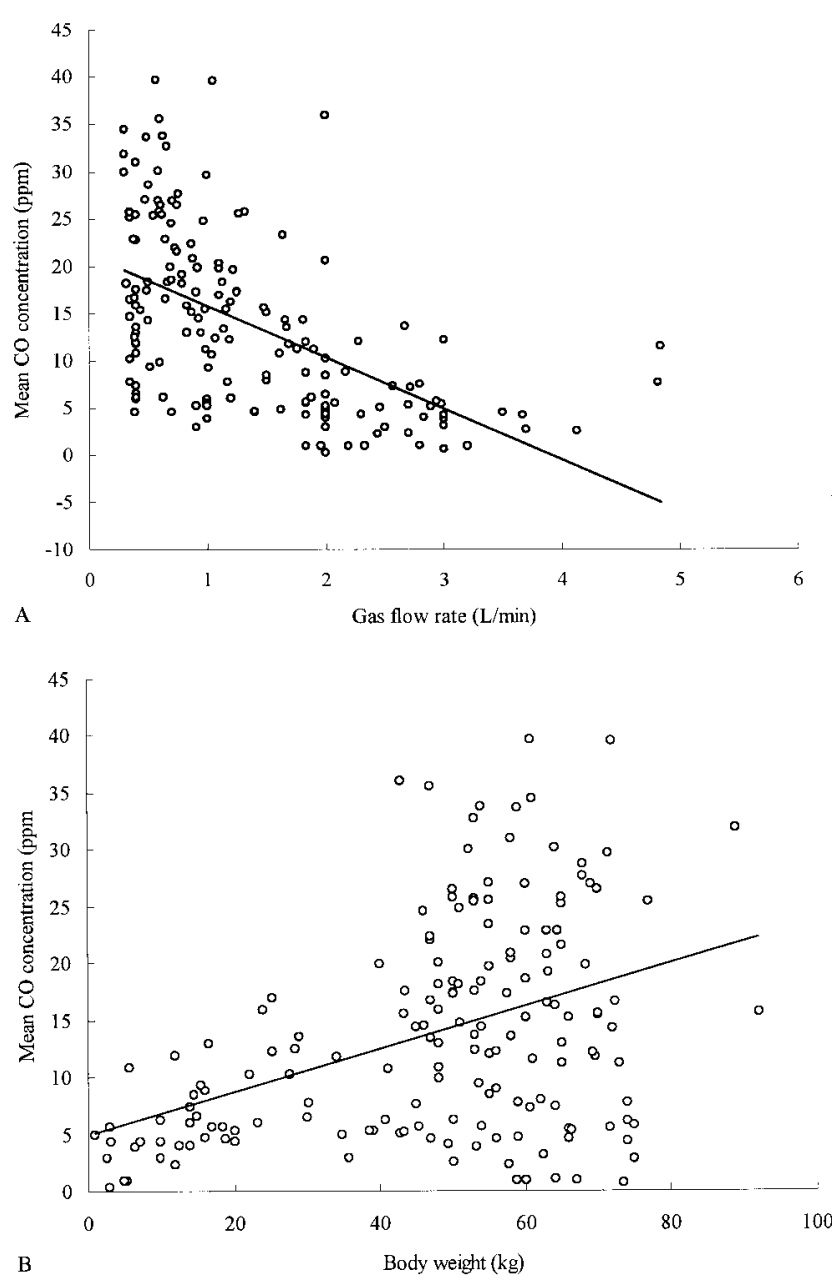

Figure 4. A, scatter plot of inspiratory mean carbon monoxide (CO) concentrations and gas flow rates for 171 nonsmokers. B, scatter plot of inspiratory carbon monoxide (CO) concentrations and patient's body weights for 171 nonsmokers.

limit) for clinical use. Thus, our CO direct measurement system can overcome the technical limitation of the GC methods and allows anesthesiologists to observe patients' $\mathrm{CO}$ exposure in real time and terminate iatrogenic $\mathrm{CO}$ poisoning in time.

We believe there are several potential applications of our monitoring system. First, we will be able to distinguish $\mathrm{CO}$ production from preoperative smoking, endogenous production and anesthetic breakdown by measuring expiratory and inspiratory $\mathrm{CO}$ concentrations simultaneously. Second, we will able to establish a dose-response relationship between $\mathrm{CO}$ concentrations in the breathing circuit and $\mathrm{COHb}$ in blood during anesthesia by combining our measuring system with $\mathrm{COHb}$ measurements for patients.

Our results also showed several useful applications for clinical anesthesia. As Woehlck et al. (3) reported, expired $\mathrm{CO}$ concentrations are a significant predictor for ST depression; we recommend monitoring intraoperative $\mathrm{CO}$ concentration continuously during anesthesia, especially for patients suffering from ischemic heart diseases. Currently CO exposure guidelines are set to maintain a $\mathrm{COHb}$ level at certain levels to avoid potential health risks associated with cardiovascular or pulmonary impairments under normal atmospheric conditions. Our results indicate that we need to reevaluate this standard of $\mathrm{CO}$ exposure under high $\mathrm{FiO}_{2}$ situations during anesthesia. The preoperative smoking rate in our study (34\%) might be underestimated; we believe smokers tend to conceal their smoking status before surgery. As expired-breath $\mathrm{CO}$ concentrations were a reasonable index for acute smoking $(16,17)$, we needed to measure alveolar CO concentrations before anesthesia to confirm preoperative smoking. Postanesthetic complications must also be monitored because $\mathrm{CO}$ is a gaseous transmitter and plays a role in neuroendocrine regulation (18).

We conclude that the major sources for increased intraoperative $\mathrm{CO}$ exposures are related to patient attributes, such as smoking status, cigarettes smoked before operation, and body weight. Increasing gas flow rates is an effective method of decreasing $\mathrm{CO}$ concentrations in the breathing circuit. Our directmeasurement $\mathrm{CO}$ system can be applied to monitor and prevent potential $\mathrm{CO}$ intoxication for patients during anesthesia. If such a $\mathrm{CO}$ monitoring system were not available during anesthesia, we could apply our model-derived factors to predict a patient's mean and peak $\mathrm{CO}$ concentrations in the breathing circuit and use the predicted results to prevent unnecessary $\mathrm{CO}$ exposure by controlling gas flow rates.

\section{References}

1. Middleton V, Poznak AV, Artusio JF, Smith SM. Carbon monoxide accumulation in closed circle anesthesia systems. Anesthesiology 1965;26:715-9.

2. Bonome C, Belda J, Alvarez-Refojo F, et al. Low-flow anesthesia and reduced animal size increase carboxyhemoglobin levels in swine during desflurane and isoflurane breakdown in dried soda lime. Anesth Analg 1999;89:909-16.

3. Woehlck HJ, Connolly LA, Cinquegrani MP, et al. Acute smoking increases ST depression in humans during general anesthesia. Anesth Analg 1999;89:856-60.

4. Fang ZX, Eger EI II, Laster MJ, et al. Carbon monoxide production from degradation of desflurane, enflurane, isoflurane, halothane, and sevoflurane by soda lime and baralyme. Anesth Analg 1995;80:1187-93.

5. Huh BK, Passannante AN, Crimmins MT. A mechanism of carbon monoxide production from volatile anesthetics and anhydrous soda lime in anesthetic circuits [abstract]. Anesthesiology 1997;87(3A):A1138.

6. Baxter PJ, Garton K, Kharasch ED. Mechanistic aspects of carbon monoxide formation from volatile anesthetics. Anesthesiology 1998;89:929-41.

7. Bonome C, Alvarez F, Soro M, et al. Experimental study about carbon monoxide production with two halogenated agents [abstract]. Br J Anaesth 1997;78:A67. 
8. Woehlck HJ, Dunning M III, Connolly LA. Reduction in the incidence of carbon monoxide exposures in humans undergoing general anesthesia. Anesthesiology 1997;87:228-34.

9. Bensinger TA, Brouiliard RP, Conrad ME. Endogenous production of carbon monoxide as measured simultaneously in blood and gas phase. Br J Haematology 1975;29:487-94.

10. Bonome $\mathrm{C}$, Alvarez F, Soro $\mathrm{M}$, et al. Carbon monoxide production in anesthesia circuit: is it safe low flows [abstract]? Br J Anaesth 1997;78:A66.

11. Soro M, Alvarez F, Bonome C, et al. Time course of soda lime dehydration within the canister in rebreathing circuits with continuous flow [abstract]. Br J Anaesth 1997;78:A68.

12. Woehlck HJ, Dunning III M, Nithipatikom K, et al. Mass spectrometry provides warning of carbon monoxide exposure via trifluoromethane. Anesthesiology 1996;84:1489-93.

13. Woehlck HJ, Dunning III M, Gandhi S, et al. Indirect detection of intraoperative carbon monoxide exposure by mass spectrometry during isoflurane anesthesia. Anesthesiology 1995;83: 213-7.
14. Baxter PJ, Kharasch ED. Rehydration of desiccated baralyme prevents carbon monoxide formation from desflurane in an anesthesia machine. Anesthesiology 1997;86:1061-5.

15. Frink EJ, Nogami WM, Morgan SE, Salmon RC. High carboxyhemoglobin concentrations occur in swine during desflurane anesthesia in the presence of partially dried carbon dioxide absorbents. Anesthesiology 1997;87:308-16.

16. Jarvis MJ, Belcher M, Vesey C, Hutchison DCS. Low cost carbon monoxide monitors in smoking assessment. Thorax 1986;41: 886-7.

17. Vreman HJ, Baxter LM, Stone RT, Stevenson DK. Evaluation of a fully automated end-tidal carbon monoxide instrument for breath analysis. Clin Chem 1996;42:50-6.

18. Brann DW, Bhat GK, Lamar CA, Mahesh VB. Gaseous transmitters and neuroendocrine regulation. Neuroendocrinology 1997; 65:85-95. 